\title{
CARACTERIZAÇÃO DAS POLÍTICAS EDUCACIONAIS NO BRASIL A PARTIR DA SISTEMATIZAÇÃO DO ESTADO DA ARTE
}

\section{CHARACTERIZATION OF EDUCATIONAL POLICIES IN BRAZIL PART OF ART STATE SYSTEMATIZATION}

\author{
ESTEVÃO, Larissa dos Santos ${ }^{1}$ \\ SILVA, Katharine Ninive Pinto ${ }^{2}$
}

\section{RESUMO}

O estudo versa sobre o estado da arte no campo das políticas educacionais considerando o cenário político-econômico do país e sua inserção na totalidade internacional, em um contexto de intensas transformações na sociedade. As reflexões e contribuição encontradas estão fundamentadas nos aportes teóricos do marxismo e apontam para três categorias: Imperialismo; Agenda Internacional para a Educação e Paradigmas na Educação. A partir dessas, compreende-se que o imperialismo, por meio dos organismos internacionais, utiliza a educação como um instrumento tanto para preparar o trabalhador com habilidades e competências exigidas pelo mercado como para prevenir distúrbios sociais diante da intensificação da exploração do capital. Nesse contexto, a pesquisa científica no campo da educação assume papel crucial na crítica aos caminhos pelos quais se têm conduzido a escola pública, objetivando a construção de uma educação científica e popular.

Palavras-Chave: Estado da arte; Políticas educacionais; Imperialismo; Agenda Multilateral para Educação; Paradigmas na educação.

\section{ABSTRACT}

The study deals with the state of the art in the field of educational policies considering the political-economic scenario of the country and its insertion in the international totality, in a context of intense transformations in society. The reflections and contribution found are based on the theoretical contributions of Marxism and point to three categories: Imperialism; International Agenda for Education and Paradigms in Education. From these, it is understood that imperialism, through international organizations, uses education as an instrument both to prepare the worker with skills and competences required by the market and to prevent social unrest in the face of intensified exploitation of capital. In this context, scientific research in the field of education assumes a crucial role in the critique of the ways in which the public school has been conducted, aiming at the construction of a popular and scientific education.

\footnotetext{
1 Mestre em Educação pela Universidade Federal de Pernambuco - UFPE, atua na linha de pesquisa Política Educacional, Planejamento e Gestão da Educação. e-mail: laure_estevao@hotmail.com

${ }^{2}$ Doutora em Educação pela Universidade Federal da Bahia. Professora do Programa de PósGraduação em Educação da Universidade Federal de Pernambuco. e-mail:katharineninive@gmail.com
} 
KeYwORDS: State of the art; Educational policies; Imperialism; Multilateral Agenda for Education; Paradigms in education.

\section{INTRODUÇÃo}

O presente estudo emerge de dissertação de mestrado concluída ${ }^{3}$ no Programa de Pós-Graduação em Educação da Universidade Federal de Pernambuco. Neste artigo, tratamos do estado da arte na área das políticas educacionais.

As pesquisas do tipo estado arte permitem sistematizar um determinado campo do conhecimento, mapeando as produções, identificando temáticas e abordagens dominantes, bem como lacunas abertas à pesquisa, definido num recorte temporal, ou seja, permite-nos apresentar um panorama geral referente a produção do conhecimento em nossa área.

Esse panorama geral nos possibilita uma visão mais abrangente do nosso campo investigativo de modo a contribuir para a identificação das questões mais relevantes e para a seleção dos estudos mais significativos para o trabalho a ser desenvolvido. Sobre esta questão, Messina (1999, p. 1) enfatiza que

Un estado del arte es un mapa que nos permite continuar caminando; un estado del arte es también una posibilidad de hilvanar discursos que en una primera mirada se presentan como discontinuos o contradictorios. En un estado del arte está presente la posibilidad de contribuir a la teoría y a la práctica de algo.

Nesse sentido, compreendemos que a análise do estado da produção do conhecimento nos permite reconhecer a contribuição de nosso estudo para o desenvolvimento do conhecimento humano e para a prática da transformação social. Isso porque, concordando com Mao Tsetung (1937, p. 1), a grande importância que o marxismo atribui à teoria é "porque ela pode guiar a atividade prática". Assim, buscamos, assim como sugerem Romanowski e Ens (2006), analisar nosso corpus documental, categorizando-o a fim de revelar os múltiplos enfoques e perspectivas existentes.

Como método de investigação, elaboramos o mapeamento do estado da arte na área das políticas educacionais considerando o cenário político-econômico do país e deste inserido na totalidade internacional. Ou seja, considerando as produções no contexto atual de intensas transformações na sociedade, de modo a apresentar um panorama geral referente às produções relativas a essa temática no período

\footnotetext{
${ }^{3}$ Título da Dissertação: "Imperialismo e Políticas Educacionais para o Ensino Médio no Brasil". Desenvolvida na Linha de Pesquisa Política Educacional, Planejamento e Gestão da Educação do Programa de Pós-Graduação em Educação da Universidade Federal de Pernambuco.
} 
compreendido entre os anos de 2013 e 2017.

Esse mapeamento se efetuou tendo como corpus documental de análise teses, dissertações e artigos publicados em periódicos disponíveis em quatro bases de dados, a saber: Banco de Teses e Dissertações da Coordenação de Aperfeiçoamento de Pessoal de Nível Superior (CAPES); Associação Nacional de PósGraduação e Pesquisa em Educação (ANPEd); Revista Brasileira de Educação (RBE) e Grupo Gestor - Pesquisa em Gestão da Educação e Políticas do Tempo Livre ${ }^{4}$.

Especificamente no Banco de Teses e Dissertações da CAPES utilizamos 06 (seis) descritores, sendo eles: "imperialismo"; "educação para todos"; "qualidade da educação"; "todos pela educação"; "BNCC" e "ensino médio".

Neste, o resultado original (sem o emprego de filtros) de estudos encontrados foram de 16.999 trabalhos, sendo a maior parte relacionados a temática do ensino médio.

Tabela 1: Resultados da revisão de literatura no Banco de Teses e Dissertações da CAPES

\begin{tabular}{cccc}
\hline Descritor & Resultado Original & Resultado Pós-Filtro & Resultado Refinado \\
\hline Imperialismo & 408 & 15 & 4 \\
Educação para todos & 292 & 63 & 4 \\
Qualidade da educação & 1.206 & 362 & 5 \\
Todos pela educação & 110 & 49 & 1 \\
BNCC & 17 & 3 & 4 \\
Ensino Médio & 14.961 & 1.384 & $\mathbf{2 0}$ \\
\hline
\end{tabular}

Fonte: Elaboração do autor (2017)

Diante da ampla quantidade de trabalhos, principalmente entre os descritores "ensino médio" e "qualidade da educação", como observados acima, empregamos ainda os seguintes filtros: Tipo - mestrado (dissertação) / doutorado (tese); Grande área de conhecimento - Ciências Humanas; Área do conhecimento - Educação; Área avaliação - Educação. Permanecendo ainda uma quantidade considerável nos

${ }^{4}$ O Grupo Gestor - Pesquisa em Gestão da Educação e Políticas do Tempo Livre foi escolhido para compor o nosso Estado da Arte por ser o grupo de pesquisa ao qual nosso estudo está vinculado, além de apresentar uma sólida discussão sobre as políticas educacionais, em especial, para o ensino médio. 
descritores já destacados, analisamos apenas os 200 primeiros trabalhos ${ }^{5}$.

Assim, ao adentrar na leitura dos títulos e resumos das produções, chegamos a um quantitativo de 20 estudos, sendo 7 teses e 13 dissertações, que de algum modo se relacionam e/ou contribuem com a área de nosso estudo.

Realizamos igualmente o levantamento do estado de conhecimento nas publicações de três reuniões nacionais da ANPEd que compreenderam o recorte temporal estabelecido. Os Grupos de Trabalho (GT's) que apresentaram aproximações com nosso estudo foram dois: Estado e Política Educacional (GT 5) e Currículo (GT 12). O resultado original de produção nesses dois GT's foi de 135 artigos e após adentrar a leitura de títulos e resumos, apuramos 9 estudos.

Tabela 2: Resultados da revisão de literatura nos GT's da ANPED

\begin{tabular}{ccc}
\hline GT & Resultado Original & Resultado Refinado \\
\hline $05-$ Estado e Política Educacional & 70 & 4 \\
$12-$ Currículo & 65 & 5 \\
\hline TOTAL & $\mathbf{1 3 5}$ & $\mathbf{9}$ \\
\hline
\end{tabular}

Fonte: Elaboração do autor (2017)

Analisamos ainda as publicações da Revista Brasileira de Educação em seus números 52 a 71, correspondente ao recorte temporal por nós estabelecido. Foram 8 os artigos encontrados que se relacionam com nossa área temática. De igual modo, analisamos as teses e dissertações do Grupo Gestor, no qual encontramos 3 dissertações.

Desta forma, após o refinamento dos estudos encontrados nas bases de dados definidas, identificamos 40 produções que pertencem a nossa área de interesse e dialogam com nosso objeto de pesquisa.

Fizemos ainda a análise comparativa das abordagens teórico-metodológicas apresentadas nessas publicações, a fim de obtermos um panorama das principais abordagens que estão sendo utilizadas nas pesquisas que dialogam com a nossa, obtivemos o resultado seguinte:

${ }^{5}$ Cabe aqui ressaltar que não se trata dos trabalhos mais recentes e sim de uma ordem própria da busca no catálogo de teses e dissertações da CAPES. 
DOI: $10.12957 / \mathrm{e}-\mathrm{mosaicos} .2019 .46470$

Tabela 3: Abordagem teórico-metodológica da revisão de literatura

\begin{tabular}{cccccc}
\hline Descritor & CAPES & ANPED & RBE & $\begin{array}{c}\text { Grupo } \\
\text { Gestor }\end{array}$ & TOTAL \\
\hline Análise de conteúdo & 1 & - & - & - & 1 \\
Ciclo de Políticas & 1 & 1 & - & - & 2 \\
Etnografia & 1 & - & - & - & 1 \\
$\begin{array}{c}\text { Materialismo histórico- } \\
\text { dialético }\end{array}$ & 13 & 2 & 2 & - & 19 \\
Neoinstitucionalista & 2 & - & - & - & 2 \\
Teoria Crítica da Sociedade & - & - & 1 & - & 3 \\
Teoria do discurso & - & 3 & - & 1 & 11 \\
Não apresenta & 2 & 3 & 5 & & 3 \\
\hline
\end{tabular}

Fonte: Elaboração do autor (2017)

O Materialismo histórico-dialético tem sido a abordagem teórico-metodológica utilizada com maior frequência nas pesquisas em políticas educacionais, o que para nós é um indício da capacidade desta perspectiva na compreensão dos fenômenos sociais e como instrumento ideológico na transformação da realidade concreta. Apesar de utilizamos esta abordagem numa perspectiva diferente da apresentada nos trabalhos por nós analisados, que seguem uma tendência principalmente marxiana-lukacsiana. Nós, neste estudo, nos embasarmos no materialismo históricodialético a partir das contribuições de Lênin e Mao Tsetung, a partir da compreensão desta como a ideologia científica do proletariado.

Por fim, distribuímos as publicações em temáticas, as mesmas utilizadas como descritores na bases de dados da CAPES: 
DOI: $10.12957 /$ e-mosaicos.2019.46470

Tabela 4: Resultado final da revisão de literatura nas bases de dados

\begin{tabular}{cccccc}
\hline Descritor & CAPES & ANPED & RBE & $\begin{array}{c}\text { Grupo } \\
\text { Gestor }\end{array}$ & TOTAL \\
\hline Imperialismo & 4 & - & 3 & - & 7 \\
Educação para todos & 4 & - & - & - & 4 \\
Qualidade da educação & 2 & 3 & 1 & - & 6 \\
Todos pela educação & 5 & - & - & - & 5 \\
BNCC & 1 & 3 & - & - & 4 \\
Ensino Médio & 4 & 3 & 4 & 3 & 14 \\
\hline TOTAL & $\mathbf{2 0}$ & $\mathbf{9}$ & $\mathbf{8}$ & $\mathbf{3}$ & $\mathbf{4 0}$ \\
\hline
\end{tabular}

Fonte: Elaboração do autor (2017)

Dessa forma, a partir das 40 produções que constituíram o nosso corpus documental de análise, organizamos as temáticas emersas dessas produções científicas em categorias que foram utilizadas para facilitar a identificação das áreas em que as produções se concentram, auxiliando na sistematização das discussões. As categorias utilizadas e sobre as quais discorreremos a seguir são: 1. Imperialismo; 2. Organismos Internacionais e Educação; 3. Paradigmas na Educação.

\section{IMPERIALISMO}

Partimos do entendimento de que é necessário compreender o atual momento de nossa sociedade, pois os fenômenos sociais estão inseridos dentro de uma totalidade histórica e contraditória (FRIGOTTO, 2009) e precisam ser analisados dialeticamente e não como fator isolado. Nesse sentido, as teses de Oliveira (2013), Mezarobba (2017) e Silva (2017), bem como a dissertação de Santos (2014) confirmam essa necessidade de compreensão da totalidade, destacando a necessidade de "compreender os determinantes sociais, concebidos no âmbito da produção capitalista, uma vez que estes são elementos preponderantes para identificar as principais contradições da sociedade brasileira" (SANTOS, 2014, p. 30) e a partir delas compreender as políticas educacionais.

Nestes estudos, o que compreendemos como imperialismo como o momento atual da sociedade capitalista, pode ser identificado norteando as análises empreendidas. Oliveira (2013), por exemplo, aponta o Imperialismo como o momento atual da sociedade capitalista, privilegiando em sua explicação a obra de Lênin - Imperialismo, Fase Superior do Capitalismo - como "a mais profunda análise das transformações do capitalismo de então" (p. 23). 
A essência do Imperialismo está na divisão do mundo entre os países opressores e oprimidos, sustentada pelo domínio do capital financeiro, na exportação de capitais e na política colonial. Silva (2017) destaca o exercício da dominação pela grandes potências imperialistas a partir de todas as formas possíveis de rapina e assinala, dos estudos de Lênin, que o Imperialismo não se caracteriza apenas pela distinção entre os países em colonizadores e colonizados, mas as formas de dominação ganham novas e complexas formas, assim países que gozam de independência política se encontram enredados em uma dependência financeira e diplomática.

Isso é o que acontece na sociedade brasileira. Silva (2017) destaca que a condição do Brasil é de país semicolonial, pois, de acordo com as relações de classes estabelecidas no seu interior, "o Estado brasileiro submete-se aos interesses dos países imperialistas, tendo em vista que é dirigido por frações da classe dominante que disputam o poder entre si, cujos interesses estão umbilicalmente ligados aos grupos imperialistas" (SILVA, 2017, p. 38).

Santos (2014) afirma que a atuação imperialista nos países semicoloniais é expansiva, ou seja, atua em todas as esferas da sociedade, política, econômica e cultural, para exercer uma plena dominação e dependência e exemplifica:

Essa dependência dos países dominados pelo imperialismo se desenvolve por meio das ações do capital financeiro que se movimenta de várias formas, na instalação de empresas para extraírem altos lucros advindos da exploração da mão-de-obra, da flexibilização dos direitos trabalhistas, da sonegação de tributos e da legislação favorável; na compra de ações já existentes; em financiamentos e empréstimos a empresas privadas e ao Estado e em investimentos no controle das fontes de recursos naturais matériasprimas, de forma a manterem um controle econômico e político dos países dominados (SOUZA apud SANTOS, 2014, p. 33-34).

Saviani (2013) exemplifica essa dependência considerando as imposições resultantes da reunião de Washington, em 1989, diante da crise estrutural do capitalismo a partir de 1970, que, através dos organismos internacionais multilaterais de financiamento, impôs as chamadas "reformas neoliberais" ${ }^{6}$, apontadas como necessárias aos países da América Latina e que implicavam em um programa de rigoroso equilíbrio fiscal tendo como vetor um profundo corte nos gastos públicos reformas administrativas, trabalhistas e previdenciárias; rígida política monetária com o objetivo de estabilização; desregulação dos mercados financeiro e do trabalho,

\footnotetext{
${ }^{6}$ Segundo Silva (2017), a expressão "reformas neoliberais" é eufemismo para as imposições imperialistas e negam "o papel hegemônico do Estado norte-americano, supondo que os ditames do mercado são algo exterior às políticas impostas pela sua rapinagem" (SOUZA apud SANTOS, 2014, p. 30).
} 
privatização radical e abertura comercial.

Em síntese, essas políticas são impostas para garantir uma sobrevida ao sistema capitalista e acabam por esconder esse caráter impositivo por serem assumidas pelas classes dominantes dos países da América Latina. São resultado da profunda crise do capitalismo, o que, a partir dos anos 1990, acarreta desdobra-se em uma ofensiva dos organismos internacionais e de sua agenda multilateral para a educação (SILVA, 2017), com a criação de uma nova ordem cultural e social (SANTOS, 2014), na busca por implementar medidas em torno da disputa do fundo público dos Estados, para garantir uma sobrevida ao Capital (HARVEY, 2016).

No Brasil, essas políticas foram assumidas pelas frações das classes dominantes que, segundo Mezarobba (2017), pretendiam reduzir o papel do Estado no desenvolvimento econômico e, em consonância com Silva (2017), têm como desdobramento a reforma do Estado, buscando uma adequação com as novas necessidades do capitalismo imerso em sua profunda crise, baseada nos conceitos "de privatização, publicização e terceirização". Tais conceitos dizem respeito à delimitação do tamanho do Estado, à desregulação que se relaciona ao nível de intervenção estatal nos mecanismos de funcionamento do mercado. No âmbito da educação, as políticas serão definidas em consonância com esses conceitos, sendo orientadas pelos Organismos Internacionais.

\section{ORGANISMOS INTERNACIONAIS E EdUCAÇÃO}

Em 1944, as nações imperialistas, sob a liderança dos EUA, criaram um sistema financeiro, uma nova ordem monetária internacional que materializa a hegemonia do poder político, econômico e financeiro dos EUA com o chamado "Acordo de Bretton Woods". Com isso, o dólar é institucionalizado como moeda mundial (PEREIRA, 2009, p.57), vinculando o desenvolvimento econômico do mundo à política fiscal e monetária norte-americana (HARVEY, 2008). Dessa forma, foram criadas diversas instituições financeiras mundiais, como o Banco Mundial e o Fundo Monetário Internacional (FMI), tendo os EUA como seu acionista majoritário e principal controlador.

Esses organismos internacionais, segundo Leher (1999), têm devastado a economia dos países semicoloniais. As classes que dirigem o Estado brasileiro estão subordinadas aos ditames dos países imperialistas, não dispõem de autonomia para dirigir o país, permitindo que as nações imperialistas se apoderem de seu aparelho estatal e que os organismos internacionais pautem suas ações, a fim de garantir a hegemonia e interesses delas em diversos setores da sociedade.

Essa submissão às determinações imperialistas reflete diretamente no campo da educação. Apresentam-se por meio da atuação do Banco Mundial que tem direcionado suas prioridades para a educação básica e permanece como principal 
agência do imperialismo, sobretudo estadunidense, tendo em vista que suas ações, além do campo financeiro, foram ampliadas para os campos político e ideológico, na medida em que se impõe sobre as políticas educacionais dos países semicoloniais, atuando como o principal difusor das ideologias imperialistas.

Segundo Souza (2010), o objetivo central do Banco Mundial é formar seres dóceis e passivos diante das imposições do capital e da miséria que se intensifica com as novas formas de organização econômica advindas da crise capitalista. Para tanto, em seus diversos documentos publicados a partir de 1990, este organismo apresenta a educação como fator de desenvolvimento econômico, bem como mecanismo de amenização, diminuição dos impactos das políticas econômicas de exploração impostas pelo imperialismo.

Silva (2017), chama atenção para a tese defendida por Leher (1999) em seu artigo intitulado "Um novo senhor da educação? A política educacional do Banco Mundial para a periferia do capitalismo". Nela, Leher (1999) defende que dentro das reformas estruturais encaminhadas pelo Banco Mundial, estava a redefinição dos sistemas educacionais que guardam íntima relação com o par governabilidadesegurança. Assim, a educação passou a ser reconhecida como um importante instrumento de dominação, pois ao invés da tradicional concentração de forças e armamentos, preconizaram-se operações coercitivas com intensa propaganda ideológica, tendo como meta evitar a influência comunista. Então, com as manifestações mais nítidas da crise estrutural do capitalismo e o aumento das tensões nos países semicoloniais, a educação passa a ser melhor situada nas prioridades do Banco, dando preferência por ações indiretas, assim desloca-se o binômio pobreza-segurança para o centro das preocupações, atuando em programas para evitar distúrbios sociais.

Assim, as diversas instituições criadas pelas nações imperialistas funcionam como instrumentos de imposição dos interesses do Imperialismo, "a política de fomento à escolarização elementar abraça [...] o tema da segurança e é um modo de construir o consentimento sem consentimento" (LEHER apud SILVA; PINHEIRO, 2014, p. 17-18).

O Banco Mundial age como ator político e ideológico na medida em que impõe políticas educacionais cujos pressupostos se propõem a justificar a dominação, difundindo a ideia de que a ausência de escolarização é a causa do atraso e da pobreza, esta como um fenômeno em si mesma e isolado do conjunto das relações sociais (PEREIRA apud SILVA, 2017), retirando das políticas de exploração impostas pelo imperialismo a responsabilidade pelo atraso social.

A educação é o maior instrumento para o desenvolvimento econômico e social. Ela é central na estratégia do Banco Mundial para ajudar os países a reduzir a pobreza e promover níveis de vida para o crescimento sustentável e investimento no povo. Essa dupla estratégia requer a promoção do uso produtivo do trabalho (o 
principal bem do pobre) e proporcionar serviços sociais básicos para o pobre (BANCO MUNDIAL apud LEHER, 1999, p. 25).

De acordo com Silva e Pinheiro (2014), essa é uma completa inversão do pressuposto marxista de infraestrutura e superestrutura, pois nela a educação assume um caráter de infraestrutura, assim "de determinada, a educação assume um papel de determinante no processo de produção da vida material" (p. 17). Essa inversão do pressuposto marxista é essencial para justificar a perpetuação do atraso social e para manter a submissão das semicolônias, buscando amenizar a visibilidade dos impactos da exploração capitalista.

O Banco Mundial é bem explicito quanto aos seus objetivos em relação à educação, que é o de atender às novas exigências do mercado de trabalho, um mercado de empregos instáveis e que necessita de trabalhadores instruídos. De acordo com Santos (2014), em função dessas novas exigências advindas da crise estrutural do capitalismo e da reestruturação produtiva do capital, a ênfase se dá na redução do poder do Estado, passando ao capital privado suas competências, através da chamada descentralização dos serviços sociais e de infraestrutura.

Com a redução e reforma do Estado brasileiro para atender às novas demandas do capital, as políticas educacionais passam a ser definidas em consonância com os mesmos princípios de privatização, publicização, terceirização e desregulação "sugeridos" pelos Organismos Internacionais. Tal reforma gerou ações de grande impacto na educação, que assume um papel estratégico. Santos (2014), destaca três objetivos que a educação passa a assumir neste novo cenário:

Atrelar a educação escolar à preparação para o trabalho e a pesquisa acadêmica ao imperativo do mercado ou às necessidades da livre iniciativa. Assegurar que o mundo empresarial tem interesse na educação porque deseja uma força de trabalho qualificada, apta para a competição no mercado nacional e internacional [...] 2. Tornar a escola um meio de transmissão dos seus princípios doutrinários. 0 que está em questão é a adequação da escola à ideologia dominante. [...] 3. Fazer da escola um mercado para os produtos da indústria cultural e da informática, o que, aliás, é coerente com ideia de fazer a escola funcionar de forma semelhante ao mercado. Contudo tornarse também contraditório porque, enquanto, no discurso, os neoliberais condenam a participação direta do Estado no financiamento da educação. Na prática, não hesitam em aproveitar os subsídios estatais para divulgar seus produtos didáticos e paradidáticos no mercado escolar (MARRACH apud SANTOS, 2014, p. 38).

Nesse sentido, Pereira (2017), em seu artigo "A política de competências e habilidades: relações educacionais entre Brasil e OCDE", apresentado em reunião da 
ANPED, afirma que, a partir da década de 1990, esses organismos retomam e reformam a lógica das competências e habilidades que demanda do mundo trabalho, objetivando "ampliar instrumentos para obtenção de hegemonia político-social para implementar programas que pudessem identificar nichos de investimento para 0 capital e ampliar suas condições de reprodução" (PEREIRA, 2017, p. 5-6), a exemplo do Programa Internacional de Avaliação dos Alunos - Pisa, criado em 1997.

Segundo Pereira (2017), há um consentimento ativo do governo brasileiro às concepções determinadas pelos organismos internacionais a fim de garantir mais desenvolvimento por meio do incentivo à produtividade dos mercados. Assim, a adequação do sistema educacional é fundamental nos processos de acumulação capitalista. A realização de reformas no âmbito da educação básica é destacada como necessária pelo Banco Mundial que busca consolidar o discurso da qualidade educacional com fins na regulação e no controle (SANTOS, 2014).

Nesse processo de busca pela conquista da chamada qualidade educacional, Paiva (2016), em sua dissertação, aponta o papel do Banco Mundial em determinar e controlar as políticas educacionais nos países semicoloniais, interferindo desde a concepção do paradigma até a elaboração da legislação que regula a educação, utilizando-se do financiamento como mecanismo histórico de subjugação e imposição de suas prioridades.

\section{Paradigmas na Educação}

No que tange ao paradigma, nesse novo contexto de reestruturação produtiva, além de reestruturar uma nova ordem econômica e política, reestrutura uma nova ordem cultural que se materializa nas ideologias impostas pelos organismos internacionais que são fundamentadas no ideário pós-moderno e reguladas pelo mercado, estendendo a lógica do capital a todas as relações sociais.

Para garantir esse novo tipo de escola, sob a bandeira de "educação para todos", nascida na Conferência Mundial de Jomtien, em 1990, novos conceitos foram difundidos nas políticas educacionais, quais sejam: "equidade, solidariedade e cooperação internacional, qualidade total, autonomia, excelência, eficácia, flexibilidade, capital humano, descentralização, poder local, formação abstrata e polivalente, participação da sociedade civil (ONGs e setor privado), ensino com novas tecnologias e superação da pobreza" (SOUZA, 2010, 155).

É nesse novo contexto dos processos produtivos que a importância da escola na formação de trabalhadores flexíveis e polivalentes, que elevem constantemente sua produtividade, visando aumentar a sua permanência no emprego, necessários ao modelo toyotista, foi reforçada, mantendo-se a crença na contribuição da educação para o processo econômico-produtivo. 
Diante disso, o Estado passa a adotar o discurso ideológico dos organismos internacionais, como já visto, que parte do pressuposto de que a educação impulsionaria o desenvolvimento econômico. Essa concepção de educação, segundo Pereira (2017) está

[...] ancorada nos fundamentos da sociedade do conhecimento e da teoria do capital humano, traduzidos na lógica de competências e habilidades [...] fazendo que os indivíduos busquem competir, ao longo de suas vidas, com o intuito de conseguir uma colocação no disputado mercado de trabalho onde não há postos para todos (PEREIRA, 2017, p. 6).

Com efeito, o processo educativo passa a ter a função de formar habilidades, atitudes e conhecimentos que garantam uma maior produtividade no trabalho, potencializando a capacidade de trabalho, assim, a educação deve ser entendida como um investimento como qualquer outro, um capital humano. Nessa concepção, a educação assentar-se em quatro eixos:

i) assemelhar escolas com empresas, com o intuito de oferecer uma formação polivalente centrada em conhecimentos rudimentares, porém úteis ao mercado de trabalho; ii) tratar a educação como treinamento e instrução de competências e habilidades individuais, estimulando a competitividade; iii) exigir, por meio de avaliações externas, as características de escola-empresa no quase-mercado educacional, objetivando a exigência de alunos preparados e adaptados às demandas do mercado; e iv) exigir e responsabilizar os estudantes e jovens pela aquisição das destrezas necessárias aos padrões capitalistas de empregabilidade (PEREIRA, 2017, p. 6).

Nesse novo paradigma, subordinado às regulações do mercado, a bandeira "educação para todos", não se apresenta como uma real democratização da educação. Todavia, Paiva (2016) aponta uma educação para uma economia do conhecimento, com negação e esvaziamento dos conhecimentos científicos acumulados pela humanidade, defendendo uma educação com aprendizagens mínimas para as classes populares. Santos (2016), em sua dissertação, também destaca essa questão, ao tratar da políticas de avaliação educacional em Pernambuco, com o que ela chama, de estreitamento curricular, com treinamento especificamente para as avaliações externas, o que melhora os índices educacionais e atende as exigências do mercado.

Rummert, Algebaile e Ventura (2013), em seu artigo para a Revista Brasileira de Educação intitulado "Educação da classe trabalhadora brasileira: expressão do desenvolvimento desigual e combinado" afirmam que o acesso ao conhecimento científico e tecnológico não se baseia mais no binômio ingresso/não ingresso na 
escola, mas no ingresso em vias formativas diferenciadas que visam alterar a universalização de índices de escolaridade sem universalizar condições de permanência e sucesso nem padrões de qualidade pedagógica.

Sob o imperativo da política de competências e habilidades, que se sustenta na difusão do lema "aprender a aprender", impõe-se à constante atualização exigida pela necessidade de ampliação da esfera da empregabilidade, ou seja, desenvolver o potencial de adaptabilidade e de empregabilidade, a capacidade de gestão do imprevisível, própria da nova ordem econômica mundial. Duarte (2001) afirma que o lema "aprender a aprender" aparece agora na sua forma mais crua, mostrando-nos seu verdadeiro núcleo: "trata-se de um lema que sintetiza uma concepção educacional voltada para a formação da capacidade adaptativa dos indivíduos" (DUARTE, 2001, p. 38).

Dentro desse contexto, o papel da escola é desenvolver uma maior capacidade de adaptação, de aprender a aprender e reaprender. E aos educadores cabe, segundo Duarte (2001), conhecer a realidade social para saber as competências que estão sendo exigidas dos indivíduos e não para fazer a crítica a essa realidade, construindo uma educação voltada para o comprometimento com a transformação radical da sociedade, evitando e criticando a "possibilidade de organizar um agir coletivo consequente" (GIOLO, 2004, p. 9). Isso é o que impõe a sociedade do Conhecimento.

Assim, concordamos com Duarte (2010), quando este afirma que a ideia comum às pedagogias hegemônicas na atualidade é a ausência de perspectiva de superação da sociedade capitalista, a exemplo das críticas feitas às políticas do imperialismo para a educação, que são neutralizadas pela crença na possibilidade de resolução dos problemas sociais sem a superação da sociedade de reprodução do capital. Segundo o autor, essas soluções estão pautadas numa visão idealista de educação onde "os problemas sociais são resultados de mentalidades errôneas, acarretando na crença de que a difusão pela educação de novas ideias entre os indivíduos, especialmente das novas gerações, levaria a superação daqueles problemas" (DUARTE, 2010, p. 35).

Outro aspecto importante sobre o paradigma, destacado por vários dos autores em nosso Estado da Arte, é a influência do grande capital privado. A medida em que se reestrutura a economia, abre-se espaço para a influência do mercado no processo educativo e para a relação existente entre fundações e instituições empresariais com a educação pública no país, o que, segundo Mezarobba (2017), permite a intromissão do capital privado na definição de políticas e projetos para a educação pública voltados a defesa dos interesses do capitalismo e diluição da luta de classes.

Segundo Paiva (2016), há um apelo explicito, por parte dos organismos internacionais, para firmar parcerias entre o setor público e o privado. 
O que mais nos chamou a atenção no documento foi o apelo explícito do Banco Mundial à iniciativa privada, chegando a criar um departamento de saúde e educação na Corporação Financeira Internacional (IFC) com o intuito de '[...] aumentar o conhecimento sobre o papel do setor privado na educação e ajudar os países a criar ambientes de política e estruturas normativas que alinhem os esforços do setor privado por meio de parcerias estratégicas [...] a fim de melhorar os sistemas educacionais' (PAIVA, 2016, p. 102).

Com efeito, o Banco Mundial utiliza de variadas formas para submeter os países semicoloniais ao imperialismo e à suas metas de desenvolvimento econômico, na educação isso tem se expressado na legitimação da atuação da iniciativa privada, gerando um grande mercado educacional, e imprimindo nas políticas educacionais 0 viés mercadológico.

Paiva (2016) destaca o Pacto Educação para Todos que associa o cumprimento de suas metas, mediante a implementação de reformas educacionais, à diminuição da pobreza. Com efeito, a educação brasileira segue o ideário pedagógico dos organismos internacionais, que, no bojo dessas reformas, prioriza a educação básica e profissional como importante instrumento para garantir uma formação mínima exigida pelo capital e superar, segundo Silva (2016), problemas sociais como desemprego, fome e todo tipo de desigualdade social, sustentadas na Teoria do Capital Humano, que enquadra tudo e todos na ótica da economia (MENDES; LIMA, 2015).

Nesse sentido, as três dissertações do Grupo Gestor - Santiago (2014), Benittes (2014) e Santos (2016) - reafirmam a inserção da lógica do setor privado, com uma política de responsabilização de toda a escola por seus resultados, numa busca por qualidade total que é a mesma apresentada pelo meio empresarial, com ênfase na eficiência, eficácia e produtividade, ou seja, uma educação voltada para a satisfação das leis do mercado, com uma proposta curricular baseada em competências e habilidades para a empregabilidade.

Dessa forma, sustentados pelo discurso da regulação e controle da qualidade da educação, o capital privado tem conseguido maior espaço de inserção, ditando as políticas educacionais no Brasil, a partir do Movimento Todos pela Educação (PIRES, 2015), que é sua maior expressão.

\section{CONSIDERAÇões FinAIS}

O percurso de elaboração do estado da arte na área das políticas educacionais, considerando o cenário político-econômico do país e sua inserção na totalidade internacional, contextualizando-as no momento atual de intensas 
transformações na sociedade em que vivemos foi de grande relevância para sistematizar o nosso campo de conhecimento e contribuir para a prática da transformação social.

Foi a partir desse estudo que pudemos comprovar a capacidade da nossa abordagem teórico-metodológica, o marxismo, na compreensão dos fenômenos sociais e como instrumento ideológico na transformação da realidade concreta.

Compreendemos ainda os determinantes sociais da totalidade histórica e contraditória do sistema de produção capitalista e como novas formas de dominação se apresentam com o Imperialismo e atuam em todas as esferas da sociedade. Para tanto, o imperialismo, principalmente, norte-americano, passa a atuar nos países semicoloniais a partir dos organismos internacionais, a exemplo do Banco Mundial, que é um importante agente de intervenção, pois, para além do campo financeiro, atua também nos campos político e ideológico.

A educação é entendida pelo Imperialismo como um importante instrumento para a dominação ideológica. Através da difusão dos pressupostos ideológicos da Teoria do Capital Humano e da Sociedade do Conhecimento, além do lema do "aprender a aprender", as nações imperialistas justificam a dominação exercida em relação aos países semicoloniais. Dessa forma, as causas do atraso social e da pobreza passam a ser justificadas através da ausência de escolarização, qualificação suficiente, de forma a difundir os pressupostos necessários para manter a submissão dos países semicoloniais.

Traduzidos na lógica das competências e habilidades, negam e esvaziam as escolas das classes populares dos conhecimentos científicos, defendendo uma educação para uma economia do conhecimento, ou seja, aprendizagens mínimas exigidas pelo capital e treinamento para as avaliações externas melhorando os índices educacionais. A intromissão do capital privado dá ênfase aos conceitos de eficiência, eficácia e produtividade, responsabilizando a escola pelos resultados, apontando a necessidade de reformas para atender às leis de mercado e uma proposta curricular voltada às competências e habilidades para empregabilidade.

O imperialismo, face a todas as mudanças implementadas nos países semicoloniais, busca atender às necessidades e dar uma sobrevida ao sistema capitalista que se encontra numa crise geral de decomposição. A educação é vista como instrumento tanto para preparar o trabalhador com habilidades exigidas pelo mercado, mas também para prevenir distúrbios sociais e movimentos contestadores da ordem, diante das imposições do capital e da miséria que se intensifica.

Dessa forma, estando a educação no campo político e ideológico, não sendo este um campo neutro e que, segundo Marx (2008), é condicionado pelo modo de produção da vida material, ela reflete as contradições principais da sociedade. É nesse contexto que a pesquisa científica no campo da educação assume papel ainda mais crucial na identificação dos caminhos pelos quais a escola pública vem sendo 
conduzida, objetivando a defesa da educação pública como um direito, particularmente, para os sujeitos das classes populares que, como outros direitos, tem sido historicamente negado.

A pesquisa científica em educação deve estar engajada na luta, nas trincheiras de democratização do conhecimento, em defesa do ensino público e a serviço do povo, atrelada à luta por uma nova sociedade, principalmente no que diz respeito à construção de possibilidades de uma educação científica e popular, "num povo que cumpra conscientemente seu processo histórico, a reorganização do ensino deve ser dirigida por seus próprios homens" (MARIÁTEGUI, 2010, p. 127) e não por ditos pensadores representantes da ideologia burguesa e perversa do capital.

\section{REFERÊNCIAS}

BENITTES, V. L. A. A política de ensino médio no estado de Pernambuco: um protótipo de gestão da educação em tempo integral. 2014. Dissertação (Mestrado) Universidade Federal de Pernambuco, Caruaru, 2014.

DUARTE, N. As pedagogias do "aprender a aprender" e algumas ilusões da assim chamada sociedade do conhecimento. In: Revista Brasileira de Educação. Rio de Janeiro, n. 18, p. 35 - 40, set./ dez. 2001. Disponível em: http://www.scielo.br/pdf/rbedu/n18/n18a04.pdf. Acesso em: 14 jan. 2015.

DUARTE, N. O debate contemporâneo das teorias pedagógicas. In: MARTINS, LM; DUARTE, N. (orgs). Formação de professores: limites contemporâneos e alternativas necessárias. São Paulo: Editora UNESP; Cultura Acadêmica, 2010. Disponível em: http://books.scielo.org/id/ysnm8/pdf/martins-9788579831034-03.pdf. Acesso em: 17 jun. 2016.

FRIGOTTO, G. Prefácio. IN: ALGEBAILE, E. Escola pública e pobreza no Brasil: ampliação para menos. Rio de Janeiro: Lamparina, Faperj, 2009, p. 17-24.

GIOLO, J. Três críticas aos sete saberes necessários à educação do futuro. V seminário de pesquisa em educação - Região Sul - V ANPED SUL, 2004. Disponível em: http://www.portalanpedsul.com.br/2004/. Acesso em: 20 set. 2016.

HARVEY, D. A transformação político-econômica do capitalismo do final do século XX. In: $A$ condição pós-moderna: uma pesquisa sobre as origens da mudança cultural. 17. ed. São Paulo: Edições Loyola, 2008.

HARVEY, D. 17 contradições e o fim do capitalismo. São Paulo: Boitempo, 2016 ( $\mathrm{p}$. 261-273). 
DOI: $10.12957 /$ e-mosaicos.2019.46470

LEHER, R. Um novo senhor da educação? A política educacional do Banco Mundial para a periferia do capitalismo. 1999. Disponível em: www.revistaoutubro.com.br/edicoes/03/out3 03.pdf. Acesso em: 22 ago. 2015.

LÉNINE, V. I. O Imperialismo, fase superior do capitalismo (Ensaio popular). In: Obras escolhidas: em três tomos. Lisboa: Edições Avante!, 1977. v. 1, p. 574-671.

MAO TSETUNG. Sobre a Prática. 1937. Disponível em:

https://www.marxists.org/portugues/mao/1937/07/pratica-ga.htm. Acesso em: 30 nov. 2017.

MARIÁTEGUI, J. C. Sete ensaios de interpretação da realidade peruana. 2. ed. São Paulo: Expressão Popular, 2010.

MARX, K. Contribuição à crítica da economia política. 2. ed. São Paulo: Expressão Popular, 2008.

MENDES, C. L.; LIMA, G. P. C. Neoliberalismo, Capital Humano e Currículo. 2015. Disponível em: http://37reuniao.anped.org.br/wp-

content/uploads/2015/02/Trabalho-GT12-4067.pdf. Acesso em: 12 dez. 2017.

MESSINA, G. Investigación en o investigación acerca de la formación docente: un estado del arte en los noventa. In: Revista Iberoamericana de Educación. n. 19. 1999. Disponível em: https://rieoei.org/historico/oeivirt/rie19a04.htm. Acesso em: 06 dez. 2018.

MEZAROBBA, G. Imperialismo e educação: a relação entre educação pública e as fundações e institutos empresariais no Brasil (1990-2014). 2017. Tese (Doutorado) Universidade Tuiuti do Paraná, Curitiba, 2017.

OLIVEIRA, F. G. R. A educação para transformação social e a consolidação da educação escolar burguesa: antagonismos, distanciamentos e aproximações. 2013. Tese (Doutorado) - Universidade Federal do Rio de Janeiro, Rio de Janeiro, 2013.

PAIVA, A. N. O viés mercadológico do programa Educação para Todos e seus desdobramentos na política educacional brasileira: uma análise onto-crítica. 2016. Dissertação (Mestrado) - Universidade Estadual do Ceará, Limoeiro do Norte, 2016.

PEREIRA, J. M. M. O Banco Mundial como ator político, intelectual e financeiro (19442008). 2009. Tese (Doutorado) - Universidade Federal Fluminense, Niterói, 2009. 
PEREIRA, R. S. A política de competências e habilidades: relações educacionais entre Brasil e OCDE. 2017. Disponível em: http://38reuniao.anped.org.br/sites/default/files/resources/programacao/trabalho 38 anped 2017 GT05 1081.pdf. Acesso em: 12 dez. 2017.

PIRES, E. C. O desvelamento do Movimento Todos pela Educação e seus desdobramentos na política educacional do estado de Goiás. 2015. Dissertação (Mestrado) - Pontifícia Universidade Católica de Goiás, Goiania, 2015.

ROMANOWSKI, J. P.; ENS, R. T. As pesquisas denominadas do tipo "estado da arte" em educação. Diálogo Educ., Curitiba, v. 6, n.19, p.37-50, set./dez. 2006.

RUMMERT, S. M.; ALGEBAILE, E.; VENTURA, J. Educação da classe trabalhadora brasileira: expressão do desenvolvimento desigual e combinado. 2014. Disponível em: http://www.scielo.br/pdf/rbedu/v18n54/11.pdf. Acesso em: 13 dez. 2017.

SANTIAGO, F. M. L. Educação e desenvolvimento em Pernambuco entre 2004 E 2014: desvelando os nexos do Programa de Educação Integral com o rejuvenescimento da Teoria do Capital Humano. 2014. Dissertação (Mestrado) Universidade Federal de Pernambuco, Caruaru, 2014.

SANTOS, M. L. S. Políticas de avaliação educacional no estado de Pernambuco: contra números, há argumentos! 2016. Dissertação (Mestrado) - Universidade Federal de Pernambuco, Caruaru, 2016.

SANTOS, M. L. F. O PDE e o gerenciamento das escolas da rede pública de Porto Velho-RO. 2014. Dissertação (Mestrado) - Universidade Federal de Rondônia, Porto Velho, 2014.

SAVIANI, D. História as ideias pedagógicas no Brasil. 4. ed. Campinas, SP: Autores Associados, 2013.

SILVA, P. A. D. A falácia da educação integral sob o domínio imperialista: um estudo do Programa Mais Educação em Rondônia. 2017. Tese (Doutorado) - Universidade Federal do Amazonas, Manaus, 2017.

SILVA, P. A. D.; PINHEIRO, M. G. S. P. Política Educacional Brasileira: uma análise a partir das categorias Imperialismo e Capitalismo Burocrático. Curitiba: 2014.

Disponível em: http://www.relepe.org/images/656.pdf. Acesso em: 14 jan 2015.

SOUZA, M. M. Imperialismo e educação no campo: uma análise das políticas educacionais no Estado de Rondônia a partir de 1990. 2010. Tese (Doutorado em 
Educação Escolar) - Universidade Estadual Paulista, Araraquara, SP, 2010. Licença Creative Commons - Atribuição-NãoComercial 4.0 Internacional.

Os direitos autorais de todos os trabalhos publicados na revista pertencem ao(s) seu(s) autor(es) e coautor(es), com o direito de primeira publicação cedido à e-Mosaicos.

Os artigos publicados são de acesso público, de uso gratuito, com atribuição de autoria obrigatória, para aplicações de finalidade educacional e não-comercial, de acordo com o modelo de licenciamento Creative Commons adotado pela revista. 